\title{
Risk, Trust, and the Interaction of Perceived Ease of Use and Behavioral Control in Predicting Consumers' Use of Social Media for Transactions
}

\begin{abstract}
There has been continued debate regarding competing models with respect to predicting use of social media. In this research the authors conceptualize and empirically test a model that combines constructs from the Technology Acceptance Model (TAM) and the Theory of Planned Behavior (TPB) together along with (1) a moderator between the two models, (2) perceived risk, and (3) trust. The empirical results support the hypothesis that perceived ease of use (from TAM theory) significantly amplifies (positively moderates) the effect of perceived behavioral control (from TPB theory) on intention to use the social media sites for transactions. In short, there are benefits to integrating concepts from the two models instead of choosing one model over the other in research and practice. The results also indicate that perceived risk and trust play significant roles as antecedents in consumer decision making, and that risk-taking propensity has a direct effect on behavioral intention.
\end{abstract}

Keywords: Social Media Network Systems (SNS); Risk-taking Propensity; Information Security; Technology Acceptance Model (TAM); Theory of Planned Behavior (TPB); Trust; Perceived Risk 


\section{Risk, Trust, and the Interaction of Perceived Ease of Use and Behavioral Control in Predicting Consumers' Use of Social Media for Transactions}

\section{Introduction}

Extant research is divided into different views on which elements influence technology adoption. One of the most widely used models to investigate an individual's adoption is the Technology Acceptance Model (TAM) (Davis, 1989; Davis, Bagozzi, \& Warshaw, 1989; Venkatesh, Davis, \& Morris, 2007). While it is simple and understandable-leading to the model being used significantly (see meta analyses in, e.g., Chen, Shing-Han, \& Chien-Yi 2011; King \& He, 2006; Schepers \& Wetzels, 2007) - it has been found that not all relationships are borne out across various studies (e.g., Bagozzi, 2007; Legris, Ingham, \& Collerette, 2003). Further research has been undertaken to try to improve upon its accuracy and predictive ability (e.g., Szajna, 1996; Venkatesh \& Bala, 2008; Venkatesh \& Davis, 2000; Venkatesh, Morris, Davis, \& Davis, 2003; Wixom \& Todd, 2005). One of the other popular models to examine behavioral intention in online settings is the Theory of Planned Behavior (TPB) - an extension of the theory of reasoned action (see Fishbein \& Ajzen, 1975).

However, scholars have criticized both TAM and TPB models as being incomplete and overlooking important concepts (Hansen, Jensen, \& Solgaard, 2004; George, 2004; Liu, Marchewka, Lu, \& Yu, 2004; Mathieson, 1991; Pavlou \& Fygenson, 2006). Indeed, Venkatesh et al. (2007) state that "the study of key antecedents and various interventions are key indicators of scientific progress and practical applicability of technology adoption research as it deepens our understanding of the phenomenon and provides levers for managerial action.” (p. 270). We believe insights can be gained by examining the integration of the two competing models in a manner that includes interaction effects of unique elements from the two competing approaches. 
At the same time there is a need to better articulate the roles of perceived risk and trust as they relate to behavioral intention. It has been stated that, in general, context influences behavior (e.g., DeLamater \& Ward, 2006); and it has been proposed that social media network systems (SNS), in particular, require a different approach to explaining/predicting individuals' use of social technologies, including accounting for risks associated with self-disclosure and risk averse behavior on social media network systems (Aral, Dellarocas, \& Godes, 2013; Benson, Saridakis, \& Tennakoon, 2015; Chen, De, \& Yu, 2015; Ha \& Stoel, 2009; Souza \& Dick, 2009; Xu, Ryan, Prybutok, \& Wen, 2012; Yan \& Tan, 2014). As to perceived risk and trust, current press, government guidelines and literature are highlighting social media network systems as the vector of choice for spreading vulnerability exploits (e.g., Anderson \& Agarwal, 2010; Dinev, Goo, Hu, \& Nam, 2009; Dinev, 2014; Mitra \& Ransbotham, 2015; Smith, Dinev, \& Xu, 2011). Concerns and fears over information security, personal data protection, and compliance are frequently reported in research as consumer barriers to adoption of social media network systems for business use (Aral et al., 2013; Boss, Galletta, Lowry, Moody, \& Polak, 2015; Leonardi, 2014). We respond to call for further research to broaden the understanding of social commerce and social media (Luo \& Lai, 2017).

The purpose of this research is to present and examine potential relationships between antecedents related to perceived risk and trust and concepts related to consumers' intentions to use of social media networks systems (aka SNS or social media) for transactions traditionally attributed to e-commerce context. ${ }^{1}$ The results of our study indicate that while both TAM and TPB constructs each explain an important part of the consumers' behavioral intention (as expected), there is a significant

\footnotetext{
${ }^{1}$ We intentionally chose to use TAM and TPB rather than derivatives such as UTAUT or UTAUT2 because the much smaller number of constructs in TAM and TPB are more parsimonious - see Bagozzi (2007) for critique of UTAUT's +50 constructs - permitting focus on the interaction involving both models and on additional antecedents. Please see the limitations section for discussion of other alternative models to TAM and TPB.
} 
interaction - that perceived ease of use (described in TAM) amplifies (i.e., positively moderates) the effect of behavioral control (described in TPB) on intention to use social media network systems for transactions. The results also indicate that the perceived risk, perceived trust, and risk-taking propensity antecedents are significant factors.

The rest of the research proceeds as follows. First, we outline conceptual logic and hypotheses. Second, we empirically test the proposed model that integrates TAM, TBP, their interaction, and perceived risk and trust related variables. Third, we assess the model and outline implications for theory and practice.

\section{Background and Hypothesis Derivation}

\subsection{TAM and TPB: Addressing the Gap}

The theory of reasoned action (TRA) proposes that attitude plays a significant role in consumers' intention to engage in behaviors (Ajzen 1987, 1991; Ajzen and Madden 1986; Ajzen and Fishbein YEAR). The theory of planned behavior (TPB) and the technology acceptance model (TAM) are each separate derivative of TRA. In particular, TPB expands TRA to include new determinants of behavioral intention including perceived behavioral control (Taylor \& Todd, 1995). And as the label suggests, "perceived behavioral control" accounts for the extent to which people perceive they actually have control over enacting the behavior of interest. The logic of perceived behavioral control draws upon the concept of self-efficacy (Bandura YEAR). That is, individuals are more likely to engage in behaviors they believe they have more control over versus behaviors that they have less control over. Around the same time as the development of TPB, other scholars outlined TAM (Davis 1989; Davis et al 1989), drawing upon TRA, which proposes a set of determinants for behavioral intentions specifically for information technology adoption. These determinants include 
perceived ease of use. Davis (1989, p. 320) defines "perceived ease of use" as the degree to which "a person believes that using the system will be free of mental effort."

We believe a significant advancement in research on predicting technology adoption and other behaviors can be made through applying the advice of Rousseau and Fried (2001, p. 4) that "A set of factors, when considered together, can sometimes yield a more interpretable and theoretically interesting pattern than any of the factors would show in isolation." In that vein, the question arises here: how can the combination of the two theories (TPB + TAM) better help us to understand consumer decision making? ${ }^{2}$ How can we apply it to future research/practice? In order to outline logic and hypothesis regarding that question, a partial formalization of the core tenets of the two theories could be compared; it would take the following form. The Theory of Planned Behavior (TPB) has two core, significant tenets: (1) Attitude-Increases in perceived ease of use should be associated with increases in perceived usefulness, and (2) Perceived Behavioral Control-Increases in perceived behavioral control are associated with increases in perceived usefulness. The Technology Acceptance Model has three core, significant tenets: (1) Attitude-increases in positive attitude should be associated with increases in behavioral intention, (2) Perceived Ease of Use- (a) Increases in perceived ease of use should be associated with increases in behavioral intention and (b) increases in perceived ease of use should be associated with increases in perceived usefulness, and (3) Perceived Usefulness - increases in perceived usefulness should be associated with increases in behavioral intention.

The partial formalization shows that both theories include "attitude" as a predictor of behavioral intention. Each has other elements not found in the other theory as listed above. Both have separately been used successfully to explain adoption of particular behaviors in many studies. At the same time, the results are not always significant, as shown the meta-analyses mentioned in the introduction

\footnotetext{
${ }^{2}$ We thank the anonymous reviewers for suggesting the inclusion of this question.
} 
section. As a result, scholarship remains divided on using TAM or TPB concepts in predicting behavioral intention of technology adoption suggesting that each approach has benefits that the other approach does not have (e.g., Aboelmaged \& Gebba, 2013; Mathieson, 1991; Pavlou \& Fygenson, 2006; Venkatesh et al., 2003). Toward reconciliation and advancing science, a few studies have looked at potential interactions within TAM and others have separately examined interactions within TPB — see Venkatesh et al. (2003) for comparisons-but no existing research has not looked at interactions that can occur from combining their unique constructs together. ${ }^{3}$ For example, perceived behavioral control (PBC) is a concept present in TPB but not TAM while perceived ease of use (PEU) is a concept present in TAM but not TPB. ${ }^{4}$ We theorize on the interaction in consumer decision making about technology adoption the next section.

\subsection{TAM and TPB Interaction}

While perceived behavioral control and perceived ease of use-as modeled separately in different prior studies - each influence technology adoption, we propose there is a possible significant interaction between perceived behavioral control (PBC) and perceived ease of use (PEU). That is, if something is seen by an individual as easier to use (PEU) but the individuals believed that they didn't have much control over it (PBC), we theorize the intention to use may be low. Likewise, if one had control over the behavior (PBC) but it was going to be much more difficult to do (PEU), we predict

\footnotetext{
${ }^{3}$ Aboelmaged and Gebba (2013) review a model that combines TAM and TPB main elements, but there are no interaction effects between distinct concepts from the two opposing models. They find-in the context of mobile banking adoption - that perceived behavioral and perceived ease of use main effects are not statistically significant, which we point out could be due (in addition to or beyond either context or sample measurement error) to interactions between those elements that are not included in the model.

${ }^{4}$ The other unique construct in TAM is "perceived usefulness" but, as an outcome of perceived ease of use, it is redundant for what we are interested in examining.
} 
that could result in apathy negating the control's positive effect on intention to use; see discussion in Hansen and Levin (2016) on apathy and motivation to use technology. However, if one had control over the behavior (PBC) and perceived that it was going to be much easier to do (PEU), than we believe the apathy shouldn't occur as the individual probably makes a more positive assessment about the chance of obtaining the desired outcome (Hansen \& Levin, 2016). This preceding logic outlines a moderating effect - that perceived ease of use (PEU) magnifies the positive effect of perceived behavioral control (PBC) on intention to use social media network systems (SNS) for transactions. Stated formally,

H1: Increased perceived ease of use amplifies (i.e., positively moderates) the association between behavioral control and the level of intention to engage in transactions through social media network systems (SNS).

\subsection{The Roles of Perceived Risk and Trust}

This research answers the call by Beldad, De Jong, and Steehouder (2010) in the seminal review for "more, and particularly more systematic, research attention for the antecedents of trust in electronic services" (p.857). Trust in organizations as second parties in online transactions is viewed as the facilitator for user's engagement in an online transaction, while the lack of trust leads to transaction aversion (Hoffman, Novak, \& Peralta, 1999), and in online economic exchanges (Ha \& Stoel, 2009), in particular. Recent developments in understanding user's behavior, in commercial and research contexts, led to heightened interest in trust and its determinants within the digital environment. As online trust is viewed as a critical success factor for online enterprise, e-services, e-communications or digital initiatives (Beldad et al., 2010). Furthermore, Bryce and Fraser (2014) highlight the relevance of trust in communication transactions. This is particularly significant when users appraise 
risk in online communicational transactions. The lack of trust and heightened perceived risk by persons involved lead to the transaction abandonment. Pavlou and Fygenson (2006) criticize both TRA and TAM as overlooking the "impersonal nature of the online environment, the extensive use of IT, and the uncertainty of the open internet" (p. 423). Related to this concept of uncertainty, other studies state that the perceived risks and trust associated with online transactions and trust in relation to online environment likely influence decision making and ultimately behavior intentions (Benson et al., 2015; Chen \& Dhillon, 2003; George, 2004; Ha \& Stoel, 2009; Hansen et al., 2004; Liu et al., 2004; McKnight, Choudhury, \& Kacmar, 2002; Saridakis, Benson, Ezingeard, \& Tennakoon, 2015). Zhou (2010) shows that high perceived risk has a destructive effect on users' initial trust in online applications, which is crucial to facilitating adoption and usage of apps. In this section we hypothesize on the relationships between risk-taking behavior, trust, constructs of TAM and TPB, and behavioral intention.

We hypothesize, in general, that users' perception of risk and trust can influence their attitudes and intentions (TAM and TPB elements) to use social media network systems for commerce. We theorize that increases in perceived risk should generally decrease TAM and TPB elements while increases in trust should generally increase TAM and TPB elements, each also affecting risk-taking propensity that in turn affects intention to use the social networking technologies for transactions.

Personal information handling and self-disclosure through social networking services are areas of major concern and are interconnected. Individuals are becoming more accustomed to considering the risk associated with transacting online. We posit that users who perceive the social technology activity as lower risk or higher trust are more likely to experiment using social networking for transactions. The findings of Ha and Stoel (2009) and Posey, Lowry, Roberts, and Ellis (2010) support the idea that trust increases online self-disclosure while privacy risk belief decreases self-disclosure. 
Individual risk-taking behavior is theorized to be predetermined at personal level (Wang, Xiao, \& Raghav Rao, 2015). We theorize that perceived risk is positively associated with ease of use, usefulness, and behavioral control in this context drawing on the logic that consumers believe that risk in technologies is decreased via security protocols/functions that of themselves make it less easy to use and thus useful and take away control from the consumer over the technology (e.g., a tradeoff). Stated formally, as it relates to engaging in transactions through social media network systems (SNS):

H2: Increased perceived risk is associated with a decrease in the level of risk-taking propensity.

H3: Increased trust is associated with an increase in the level of risk-taking propensity.

H4: Increased perceived risk is associated with an increase in the level of perceived ease of use.

H5: Increased trust is associated with an increase in the level of perceived ease of use.

H6: Increased perceived risk is associated with an increase in the strength of attitude (i.e., on need for guarding information sharing in technology usage).

H7: Increased trust is associated with an increase in the strength of attitude (i.e., on need for guarding information sharing in technology usage).

H8: Increased perceived risk is associated with an increase in the level of perceived behavioral control.

H9: Increased trust is associated with an increase in the level of perceived behavioral control.

H10: Increased risk-taking propensity is associated with an increase in behavioral intention.

\subsection{Existing TAM and TPB Models}

The technology acceptance model focuses on the contributions of perceived usefulness, perceived ease of use, and attitude toward the behavior in predicting and explaining behavioral intention. Since its seminal appearance (Davis et al., 1989), multiple meta-analyses of extant TAM research indicate that hundreds of studies have focused on investigating and extending TAM theory in different 
contexts (King \& He, 2006; Ma \& Liping, 2004; Schepers \& Wetzels, 2007; Venkatesh et al., 2003). Business research successfully applied TAM in a variety of settings such as: handheld devices (Bruner \& Kumar, 2005), differing demographics (Porter \& Donthu, 2006), internet banking (Alsajjan \& Dennis, 2010), SMS advertising (Muk \& Chung, 2015), mobile advertising (Yang, Kim, \& Yoo, 2013), and traditional e-commerce (Ha \& Stoel, 2009). Thus, we recognize - i.e., important but not new - hypotheses (control hypotheses, as we call them here) from that literature in the model applied to the context of consumers using social media network systems (SNS) for transactions:

Control Hypothesis C1: Increases in perceived ease of use are associated with increases in perceived usefulness of engaging in transactions through social media network systems (SNS).

Control Hypothesis C2: Increases in perceived ease of use are associated with increases in behavioral intentions to engage in transactions through social media network systems (SNS).

Control Hypothesis C3: Increases in perceived usefulness are associated with increases in behavioral intentions to engage in transactions through social media network systems (SNS).

Control Hypothesis C4: Increases in positive attitude are associated with increases in behavioral intentions to engage in transactions through social media network systems (SNS).

TPB predicts behavioral intention through the constructs of attitude toward the behavior and perceived behavioral control (Taylor \& Todd, 1995). The TPB has been used in business research to examine entrepreneurial intentions (Carr \& Sequeira, 2007; Fayolle \& Liñán, 2014), physical store shopping behavior (Darden \& Dorsch, 1990), internet store shopping behavior (Smith \& Sivakumar, 2004), social influence and high tech innovations (Kulviwat, Bruner II, \& Al-Shuridah, 2009), and innovation adoption (Frambach \& Schillewaert, 2002), among other topics.

The "attitude" construct is present in both TAM and TPB models, and we have already recognized attitude's theorized role in control hypothesis $\mathrm{C} 4$. The distinct contribution of the main TPB model 
is perceived behavioral control ( $\mathrm{PBC}$ ), which has a generally recognized positive relationship in TPB literature between perceived behavioral control and behavioral intention. Consistent with that previously cited literature we propose:

Control Hypothesis C5: Increases in perceived behavioral control are associated with increases in behavioral intentions to engage in transactions through social media network systems (SNS).

Based on the above considerations we propose a conceptual model predicting the use of social media network systems (SNS) for transactions shown in Figure 1. To sum up, we introduce a new moderating hypothesis related to the interaction between the technology acceptance model (Davis et al., 1989) and the theory of planned behaviour (Taylor \& Todd, 1995). Furthermore, we introduce hypotheses on the antecedent roles of perceived risk, trust, and risk-taking propensity. Finally, we consider important control hypotheses established in two of the most utilized models of technology adoption prediction: The next section describes the methodological approach.

\section{$<<$ Insert Figure 1 about here $>$}

\section{Method}

\subsection{Sampling and Study Design}

As to study design, a cross-sectional, national survey was conducted consistent with studies using TAM or TPB to predict behavioral intention. The final study sample consisted of 318 UK consumers recruited through an email campaign containing an invitation to participate in an online survey about social media use. (See, e.g., Krejcie \& Morgan, 1970). The survey was structured to allow data collection from active social platform users and a criterion has been introduced to eliminate answers by individuals which may have arrived to the survey link bypassing the registration requirements. 
Survey scale items are shown in Table 1. As to national sample representativeness, respondents were 59\% female (129 males, 189 females). Nearly $23 \%$ had earned a bachelors degree and $8 \%$ a masters or doctoral degree. Age distribution was $18-28=16 \%, 29-38=19.8 \%, 39-48=23.3 \%, 49-58=26.1 \%$, $59-68=14.8 \%$. As to occupation, nearly $35 \%$ held professional or managerial roles, $38 \%$ held technical or skilled positions, $20 \%$ held unskilled positions, and $6 \%$ were students.

\subsection{Measures}

As for social media network systems (SNS) transactions, many firms have created commercial presence on social media network systems and are exploiting social commerce opportunities (Abrams, 2014). Survey questions are adapted from Davis et al. (1989) for TAM elements and Taylor and Todd (1995) for TPB elements using seven point Likert scales. Following Chin, Marcolin, and Newsted (2003), the moderator was calculated by multiplying scale items of PEU and PBC. Scale items and detailed psychographic properties appear in Table 1.

\section{<<Insert Table 1 about here〉>}

Single-respondent studies inherently can possess some level of common method variance (aka, CMV, common source bias). Palmatier (2016, p. 656) states "Since CMV reduces the power to find significant interaction effects, moderating hypotheses are not undermined by the CMV in survey data and thus offers more potential contribution." While one of the central contributions of this research is the inclusion of an interaction coefficient to examine the proposed moderating hypothesis (H1), we also still minimized the potential for common source through several procedural and statistical techniques mentioned in Podsakoff, MacKenzie, Lee, and Podsakoff (2003, p. 899), as they mention 
that "there is no single best method for handling the problem." As to procedural remedies, we attempted to increase the psychological separation of the variables by counterbalancing the variables order of measurement via separated cover stories for criterion versus predictor variables; furthermore, the variables presented in several different subsections on different pages (so respondents would have to pause and read each page's instructions). Different response formats were used across different subsections. Extensive pretesting was used. Survey respondents were guaranteed anonymity. As to statistical remedies a post hoc Harman's single factor test showed that no single factor accounts for the majority of the variance in the unrotated factor matrix. Including the highest factor on the model as a control variable on the dependent variables did not produce a significant change in variance explained. A seemingly unrelated CFA marker variable explains only a very small percentage of the variance (Podsakoff, MacKenzie, \& Podsakoff, 2012). And last, we note that any potential method bias is not able to account for any statistically significant interaction effects as noted in Podsakoff et al. (2012). Thus, common source bias does not appear to be a significant issue.

\subsection{Analysis}

We used partial least squares (PLS) component-based structural equation modeling because of the predictive focus, testing of interaction terms of latent variables, sample size and number of paths (e.g., Chin et al., 2003; Hansen \& Levin, 2016; Wold, 1982). SmartPLS 2.0 software was used for the PLS regression analysis (MacMillan, Money, Money \& Downing, 2005). We used a bootstrap of 500 resamples to assess the parameter estimate significance because partial least squares regression is a distribution-free technique (e.g., Henseler, Ringle, \& Sinkovics, 2009). T-values were computed based on the bootstrapping procedure and their significance levels were determined using a two-tailed distribution with 499 degrees of freedom (Ringle, Wende, \& Will, 2005). 
As to the measurement model, all individual scale items' reliability exceeds the standard 0.7 minimum value. Discriminate validity of the constructs is established using two methods. First, cross loading was not determined to be an issue; each item loaded on the intended construct and not another construct. Second, the square root of the AVE exceeded the inter-item correlation values for each construct, indicating discriminant validity has been achieved (Grégoire \& Fisher, 2006). Table 2 contains the latent variable correlations. The 0.81 goodness-of-fit (GoF) index is considered acceptable (Henseler, Hubona, \& Ray, 2016; Tenenhaus et al., 2004); Wetzels et al. (2009) propose the following GoF index interpretation: GoF of $0.1=$ small effect, GoF of $0.25=$ medium effect, and GoF of .36 = large effect. To establish predictive criteria, we use the Stone-Geisser's Q2 (Geisser, 1975; Henseler et al., 2009; Stone, 1974), which was measured using a blindfolding technique in which all endogenous values that are positive are considered predictive (Wold, 1982).

\section{$<$ Insert Table 2 about here $>>$}

\section{Results}

Figure 2 shows the path coefficients. To overview, we find support for 4 of 5 of the control hypotheses and 10 of 10 of the new hypotheses in the context behavioral intention to use social networking systems for transactions.

As to the generally acknowledged core elements drawn from TAM in the control hypotheses (control hypotheses C1-C5), perceived ease of use (path coefficient $=0.12 \mathrm{t}=2.41 ; \mathrm{p}<0.05$ ) has a significant positive effect on the level of behavioral intention. Perceived ease of use (path coefficient $=0.36 \mathrm{t}=6.96 ; \mathrm{p}<0.01)$ also has a significant positive effect on the level of perceived usefulness. In turn, perceived usefulness (path coefficient $=0.20 \mathrm{t}=3.35 ; \mathrm{p}<0.01$ ) has a significant positive effect on behavioral intention. As to the shared element in TAM and TPB of attitude toward the behavior, attitude (path coefficient $=-0.08 \mathrm{t}=1.67 ; \mathrm{p}=\mathrm{n} . \mathrm{s}$.) has an insignificant average effect on 
the level of behavioral intention. As to the generally acknowledge, but distinct, core element drawn from TPB perceived behavioral control (path coefficient $=0.15 \mathrm{t}=2.34 ; \mathrm{p}<0.05$ ) has a significant positive effect on behavioral intention. To summarize, we find support for 4 of 5 control hypotheses in the context of consumers using social networking sites for transactions traditionally performed through traditional e-commerce business Web sites.

\section{$<$ Insert Figure 2 about here $>>$}

As to the new moderation hypothesis $(\mathrm{H} 1)$, the results indicate support that increased perceived ease of use amplifies (path coefficient $=0.09 t=1.98 ; p<0.05$ ) the effect of behavioral control on the level of intention to engage in transactions through social media network systems (see figure 3). We believe this result has important implications for research on TAM and TPB; the results are consistent with the idea that using TAM or TPB separately in research or measurement does provide value, but it does not accurately capture how perceived ease of use (PEU) and perceived behavioral control (PBC) interact in affecting behavioral intention. In the context and sample of this study, the $\mathrm{R}^{2}$ of Behavioral Intention increases from 0.166 when including only TPB antecedents in the PLS SEM model or 0.221 when only including TAM antecedents in the PLS SEM model for this sample and context to 0.258 when the $\mathrm{BC}$ x PEU moderator is added to the model. Adding trust and risk to the model increases the $\mathrm{R}^{2}$ to 0.323 .

\section{$<$ Insert Figure 3 about here $>>$}

The level of perceived risk has a significant negative association with risk-taking propensity (path coefficient $=-0.15 \mathrm{t}=2.49 ; \mathrm{p}<0.05)$, supporting $\mathrm{H} 2$. This primary path is important given the significance of the $\mathrm{H} 9$ path from risk-taking propensity to behavioral intention as discussed in the 
next paragraph. Perceived risk has a significant positive association with perceived ease of use (path coefficient $=0.13 \mathrm{t}=2.27 ; \mathrm{p}<0.05$ ), attitude [toward the need for social media network systems security] (path coefficient $=0.40 \mathrm{t}=8.95 ; \mathrm{p}<0.01$ ), and behavioral control (path coefficient $=0.16 \mathrm{t}$ $=2.33 ; \mathrm{p}<0.05$ ), consistent with $\mathrm{H} 4, \mathrm{H} 6$, and $\mathrm{H} 8$. That is, the results are consistent with the process logic that consumers, on average, believe that technologies that have less risk via increase security measures/design are not as easy to use, as useful, and they have less control over them because of the increased security protocols (e.g., such as ease of use of blackberry smartphones vs apple smartphones). Alternatively, it could be the case that individuals who indicate higher scores on perceived ease of use, perceived usefulness, and behavioral control are also inherently more aware of the perceived risks - which is a natural limitation of cross sectional studies. Future research looking at this topic would be helpful, as it is beyond the scope of the study here.

We find that perceived trust is positively associated with risk-taking propensity (path coefficient $=0.29 \mathrm{t}=5.06 ; \mathrm{p}<0.01$ ), perceived ease of use (path coefficient $=0.30 \mathrm{t}=5.65 ; \mathrm{p}<0.01$ ), attitude (path coefficient $=0.18 \mathrm{t}=3.87 ; \mathrm{p}<0.01$ ), and behavioral control ( ath coefficient $=0.64 \mathrm{t}=18.65$; $\mathrm{p}<0.01$ ), supporting $\mathrm{H} 3, \mathrm{H} 5, \mathrm{H} 7$, and $\mathrm{H} 9$.

As to $\mathrm{H} 10$, we find that increased risk-taking propensity (path coefficient $=0.40 \mathrm{t}=8.29 ; \mathrm{p}<0$ .01) has a significant positive effect on behavioral intention, supporting H10.

\section{Discussion}

\subsection{Theoretical Implications}

Social media media network systems (SNS) offer commercial opportunities in the market. As noted by Bharadwaj, Sawy, Pavlou, and Venkatraman (2013), many firms have begun to see the power of social media technologies to create new IT capabilities and to develop new strategies around services and products. However, wanting consumers to use social media does not equate to usage (Hansen \& 
Levin, 2016). This paper examines the interaction of TAM and TPB concepts (PEU + PBC) plus the roles of perceived risk, perceived trust, and risk-taking propensity in the context of social media network systems. Prior research has looked at potential interactions within TAM or interactions within TPB — see Venkatesh et al. (2003)—but not at interactions from combining their unique constructs.

Criticisms of TAM as a theory include its limited explanatory and predictive power. The results of this present research significantly support the idea that elements unique to TAM (perceived ease of use) and TPB (perceived behavioral control) have significant positive interactions in predicting behavioral intention. In particular, the results indicate support that the main effects of perceived ease of use from TAM and perceived behavioral control from TPB do not always hold true. Rather, they influence one another-that when using the social networking site for transactions is seen by consumers as easier to use (PEU) but the consumers believed that they do not have much control over it $(\mathrm{PBC})$, the intention to use it might not be very high. Or, when consumers perceive they have more control over the behavior (PBC) but perceive it is going to be much more difficult to do (PEU) there is a diminished intention to use.

This research also shows the perceived risk and trust are important antecedents for models examining behavioral intention to use social technologies. Both perceived risk and trust have significant effects on individuals' risk-taking propensity, which in turn has a significant effect on behavioral intention. Risk and trust can be difficult and complex to empirically model in research because they can be related to many different elements (e.g., endogeneity). The results are consistent with the idea that that perceived risk and trust are counterbalances in a persons' identified risk-taking propensity. 


\subsection{Practical Implications}

High perceived risk has been shown as detrimental in building users' initial trust (Zhou, 2010). Young people, a major proportion of social platform users, display a high level of awareness of online risks which influence their decisions to transact (Bryce \& Fraser, 2014). Trust is crucial to the effective adoption and usage of online systems, from banking to social media network systems. One of the important findings from this research regards the risk-taking behavior of social users. An increase in perceived risk about security does appear to decrease risk-taking propensity, and in turn, risk-taking propensity significantly impacts behavior intention. An increase in perceived trust, on the other hand, is found to increase risk-taking propensity, and in turn, behavioral intention. Thus, social platform vendors should implement activities that could either decrease perceived risk or increase perceived trust. For example, they could offer awareness programs for social media users to avoid loss of information and cyber victimization owing to the overly risky behaviors and establishment of security enhancing culture. Overall the results of this research offer a positive outlook for social commerce as risk and trust can be managed effectively by social platform vendors.

Many designers in practice often believe a key barrier to adoption is lack of friendliness. However, simply focusing on showcasing the ease of use of a new technology does not result in consumers increasing their intentions to adopt the new technology - unless the organization also emphasizes the ability of consumers to have behavioral control. Thus, companies need to effectively convey/show that consumers have both ease of use and behavioral control; see Figure 3. The study results help clarify conclusions by Davis et al. (1989) that found mixed support when comparing TRA and TAM theoretical models. The present research shows that by introducing the moderator (PEU x PBC) in addition to the antecedent roles of perceived risk, trust, and risk-taking propensity, we can better explain the behavioral intention to transact on social media network systems (SNS). 


\subsection{Limitations and Future Research Opportunities}

The results of our study are important and help inform the research community and industry by expanding the knowledge base of user behavior intentions for transacting on social media. Although this research provides new insights, it has limitations and raises a number of new research questions. It is conceivable that larger samples could yield a different outcome and we therefore open the proposed model to further empirical studies in both national context and on international samples of respondents. We describe four opportunities for future research arising from limitations given choices that had to be made in the research focus and study design.

The first limitation and opportunity relates to the full range of emotions that could impact behavioral intention. Researchers concur that cognitive processing and level of behavioral change, the basis of TBP, impose limits on the explanatory powers of the model on user behavior. In particular, in comparison to the affective processing models, TPB does not take into account emotional constructs, including threat, fear, mood and feelings of negativity (or the opposite of thereof), see, e.g., Hansen and Levin (2016) and Miao, Evans, and Zou (2007). While we addressed the user perceptions of risk and trust, as well as attitude on need for social media network systems security and individual risk-taking propensity, investigating the full range of emotions in behavioral intention on social network technology adoption would be an interesting, important extension of the proposed research model. Related, the model could be applied to respondents in different locations.

The second limitation and opportunity relates to context. As shown by (Fu \& Shumate, 2017) in the current digital media landscape, individuals use and are influenced by their experience with multiple social media network systems. Different forms of social media network systems offer 
different levels of media richness, amount of self-disclosure, and cognitive effort. Thus, the model could be applied to different forms of social media network systems.

The third limitation and opportunity relates to method. This study uses a cross sectional sample of respondents consistent with prior research on TAM and TPB concepts. While there is significant variation in the reported scores on risk and trust, they are not manipulated in an experimental design, and thus, as pointed out by one of the reviewers, there is the possibility that the results might be context specific; future research that uses direct manipulation of risk and trust in experimental design would increase the range of the external validity of the present results.

The fourth limitation and opportunity relates to consideration of elements found in other predictive models of technology adoption. It can be difficult to evaluate the full potential of a new model without modeling the range of alternatives. While the focus here was on TAM and TPB comparisons and interactions, we hope future research would examine interactions with concepts from yet other technology adoptions models such as the 'motivation model' that focuses on intrinsic, extrinsic, and/or apathetic motivations (see Hansen \& Levin, 2010, 2016; Levin \& Hansen, 2008; Levin, Hansen \& Laverie, 2012) or UTAUT (see Venkatesh et al., 2003). We intentionally did not attempt to examine UTAUT given prior criticism regarding the enormous number (more than 50) of constructs (e.g., Bagozzi, 2007); there simply was not room in the survey instrument to include all of the constructs from UTAUT in addition to existing constructs. That is a reality that all surveys in practice face: the tradeoff of adding several more pages of survey scales in attempt to provide more insight (or in this case variance explained). Indeed, our purpose was to compare the most popular, parsimonious (involving very few constructs) models. However, future research (involving multiple studies given the number of elements) could look at interactions between TAM, TCB, Motivation Model, and UTAUT and other models, such as those listed in Hansen and Levin (2016). 


\section{Conclusion}

Social media technologies permit many commercial opportunities. However, wanting customers to use social media networks for transactions does not equate to usage. This research shows that-over and beyond the generally recognized effects of TAM or PBC main elements - the connection between perceived behavioral control (PBC) and behavioral intention is amplified or diminished depending on the perceived ease of use (PEU). Thus, research on technology adoption is improved when it combines elements from both the technology acceptance model (TAM) and theory of planned behavior (TPB) instead of focusing on tension between which of the two model is more correct; they both add value and their interaction adds even more value in explaining intention to adopt the social media technology for commerce. The results show that taken alone increases in perceived behavioral control do not always translates into increases in intention to use the social media network systems (SNS). Also, the results indicate that perceived risk and trust play important, opposing roles in the formation of risk-taking propensity beliefs that impact intention to use the social media to transact through social media network systems. 
Figure 1. Theorized Model

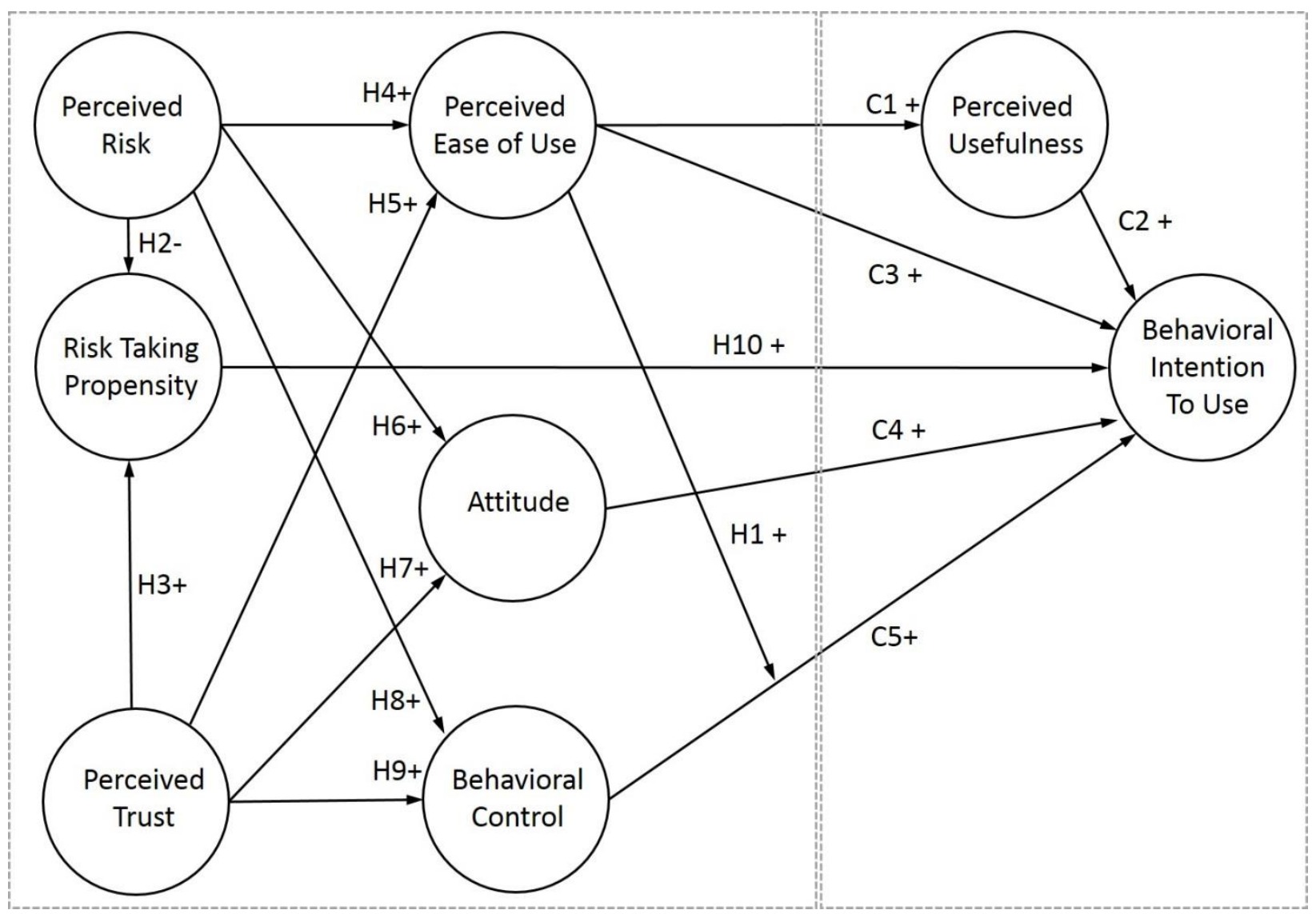

Note: As the foremost contribution is the interaction of PEU and PBC, attention is first focused there (on H1), and then the model proceeds from left to right (H2 to H10). PEU, PU, and Attitude are traditional driving factors in the TAM model, whereas PBC and Attitude are traditional driving factors in the TPB model. Here they are combined and a moderator (PEU x PBC) is introduced (H1) in addition to the antecedent roles of perceived risk, trust, and risk-taking propensity. 
Figure 2. Results of Structural Equation Modelling

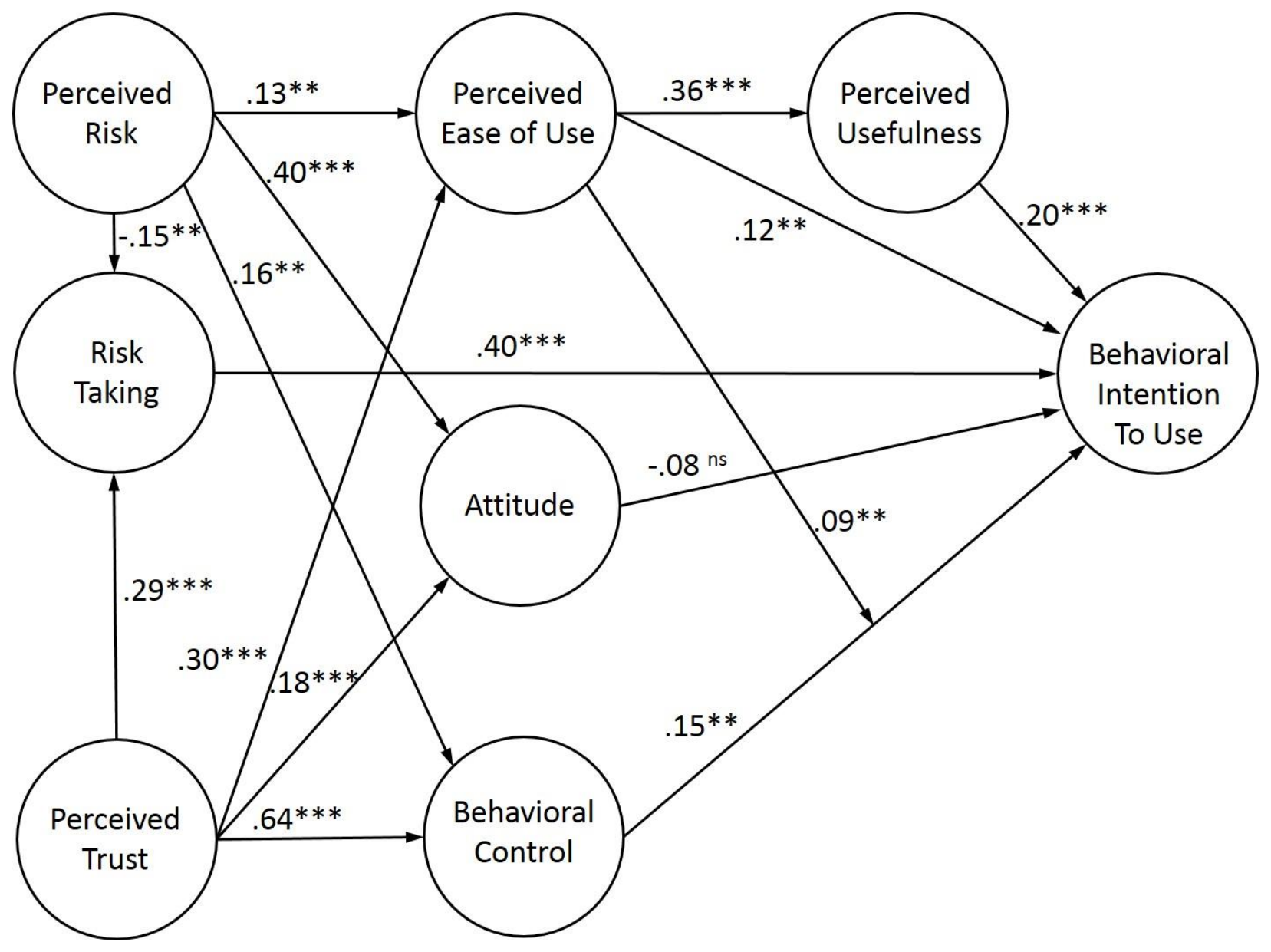

Note: $* \mathrm{p}<0.10, * * \mathrm{p}<0.05, * * * \mathrm{p}<0.01$. 
Figure 3. Chart of the Significant Interaction of Perceived Behavioral Control (from TPB) and Perceived Ease of Use (from TAM)

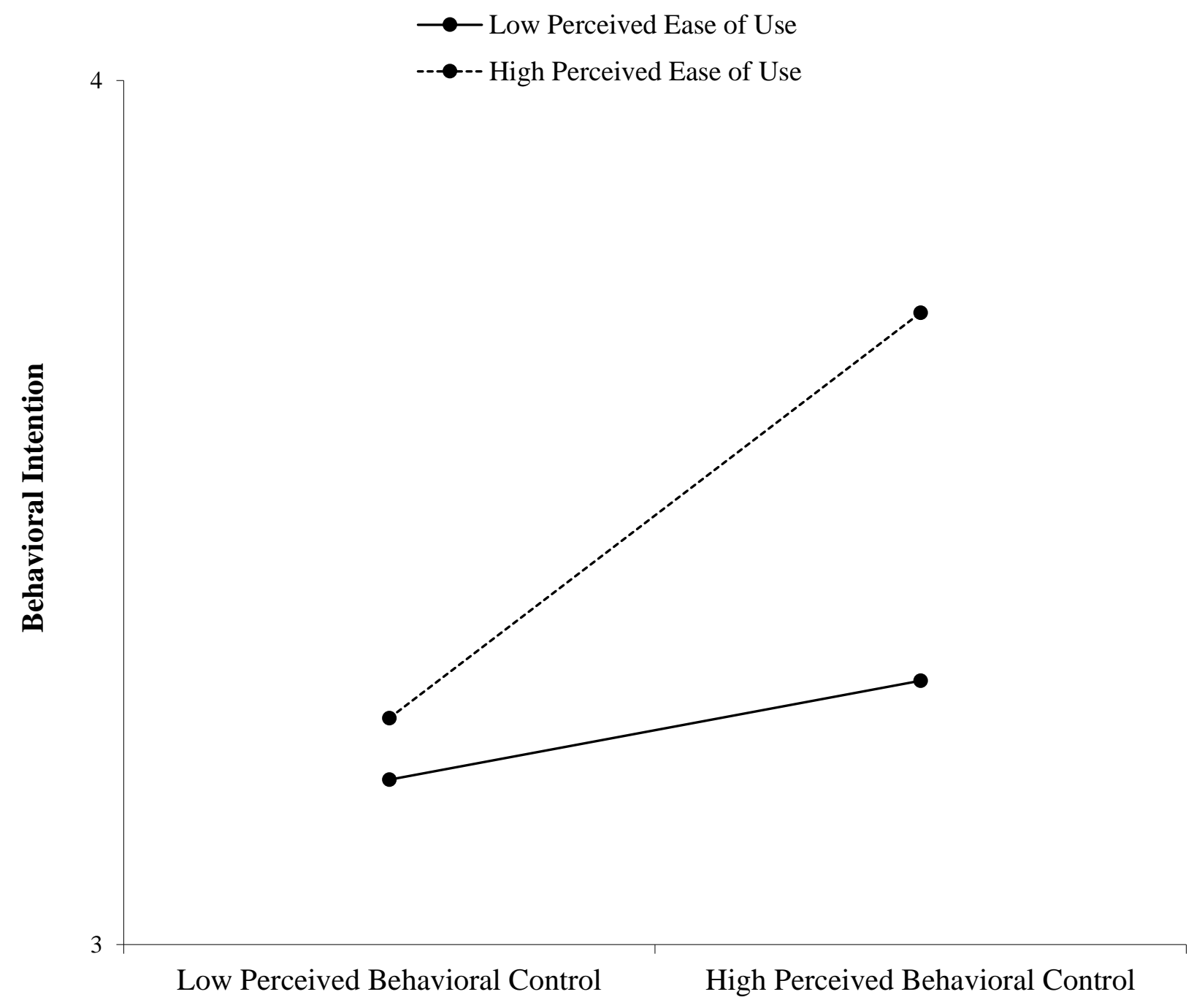


Table 1. Constructs exhibit Reliability and Convergent Validity

\begin{tabular}{l} 
Construct \\
\hline Behavioral Intention (Reliability 0.97, AVE 0.93, Alpha 0.96)
\end{tabular}

...I will buy from SNS in the future

...I often consider buying from SNS

...I have strong intentions to purchase from SNS in the future

Perceived Ease of Use (Reliability 0.94, AVE 0.79, Alpha 0.93)

...I am extremely skillful at using the Web

...I know somewhat more about using the Web than most people

...I feel confident working on a personal computer

...I feel confident understanding terms/worlds relating to computer hardware

...I feel confident understanding terms/worlds relating to computer

software

Perceived Usefulness (Reliability 0.84, AVE 0.59, Alpha 0 .74)

...My private information is managed securely by Social Networking

Sites (SNS) I transact with

...I am sure that payment information exchanged with SNS will be protected

...The SNS I visit provides detailed information about security

...Compared to others, I am more concerned about the way SNS handles personal information

Attitude (Reliability 0.98, AVE 0.94, Alpha 0.96)

...SNS should not use personal information for any purpose unless the individual who provided information has authorized it

...When people give personal information to a SNS for some reason, the online company should never use the information for any other reason

...SNS should never sell the personal information in their computer databases to other companies

Behavioral Control (Reliability 0.81, AVE 0.54, Alpha 0 .72)

...I make sure that online forms on SNS are secure before filling out information

...I set my browser to reject unnecessary cookies from SNS

...I believe I have control over how personal information is used by SNS

...I believe I can control my personal information provided to SNS

Risk-taking propensity (Reliability 0.93, AVE 0.83, Alpha 0 .89)

...I am willing to take substantial risks to do online shopping.

...I am willing to accept some risk of losing money if online shopping is likely to involve an insignificant amount of risk.

...I am willing to accept some risk to my personal information if online shopping is likely to involve an insignificant amount of risk.

Mean S.D. Loading

$\begin{array}{lll}3.5 & 1.6 & 0.96\end{array}$

$\begin{array}{lll}3.3 & 1.7 & 0.97\end{array}$

$\begin{array}{lll}3.2 & 1.7 & 0.95\end{array}$

$\begin{array}{lll}4.3 & 1.6 & 0.84\end{array}$

$\begin{array}{lll}4.2 & 1.6 & 0.87\end{array}$

$\begin{array}{lll}4.6 & 1.8 & 0.91\end{array}$

$\begin{array}{lll}4.6 & 1.6 & 0.92\end{array}$

$\begin{array}{lll}4.4 & 1.6 & 0.88\end{array}$

$\begin{array}{lll}4.1 & 1.6 & 0.87\end{array}$

$\begin{array}{lll}4.0 & 1.6 & 0.87\end{array}$

$\begin{array}{lll}4.1 & 1.6 & 0.89\end{array}$

$\begin{array}{lll}4.9 & 1.6 & 0.84\end{array}$

$\begin{array}{lll}2.4 & 1.6 & 0.97\end{array}$

$\begin{array}{lll}2.3 & 1.5 & 0.97\end{array}$

$\begin{array}{lll}2.5 & 1.7 & 0.96\end{array}$

$\begin{array}{lll}3.6 & 1.9 & 0.66\end{array}$

$\begin{array}{lll}3.2 & 1.8 & 0.66\end{array}$

$\begin{array}{lll}3.2 & 1.8 & 0.91\end{array}$

$\begin{array}{lll}3.3 & 1.8 & 0.88\end{array}$

$\begin{array}{lll}2.9 & 1.8 & 0.87\end{array}$

$\begin{array}{lll}2.7 & 1.7 & 0.93\end{array}$

$\begin{array}{lll}2.8 & 1.7 & 0.93\end{array}$ 
Perceived Risk (Reliability 0.97, AVE 0 .91, Alpha 0.95)

...In general, it would be risky to give (information) to SNS.

$\begin{array}{lll}5.0 & 1.3 & 0.94\end{array}$

...There would be high potential for loss associated with giving (information) to SNS

...There would be too much uncertainty associated with giving

$\begin{array}{lll}4.9 & 1.4 & 0.96\end{array}$ (information) to SNS

$\begin{array}{lll}4.9 & 1.3 & 0.95\end{array}$

Trust (Reliability 0.94, AVE 0 .71, Alpha 0.92)

...SNS are trustworthy

$\begin{array}{lll}4.0 & 1.3 & 0.86\end{array}$

...SNS wants to be known as one who keeps promises and commitments

$\begin{array}{lll}4.4 & 1.3 & 0.75\end{array}$

...I trust that SNS keeps my best interests in mind

$\begin{array}{lll}4.0 & 1.4 & 0.84\end{array}$

...I think that SNS have sufficient technical capacity to ensure that no other organization will supplant its identity on the Internet.

...I think that SNS have sufficient technical capacity to ensure that the data I send will not be intercepted by hackers

...I think that SNS have sufficient technical capacity to ensure that the

$4.4 \quad 1.5 \quad 0.85$

data I send cannot be modified by a third party.

Note 1: In the introduction, respondents were informed that SNS would be used to refer to social media network systems.

Note 2: Constructs are measured using 7 point scales as described in more detail in the text.

Note 3: C1 to C6 are control hypotheses (expected from extant research; important but not new). 
Table 2. Correlations for Key Constructs are Significant

\begin{tabular}{|c|c|c|c|c|c|c|c|c|}
\hline & 1 & 2 & 3 & 4 & 5 & 6 & 7 & 8 \\
\hline 1. Attitude & 0.97 & & & & & & & \\
\hline 2. Behavioral Control (BC) & 0.15 & 0.74 & & & & & & \\
\hline 3. Behavioral Intention & -0.12 & 0.36 & 0.96 & & & & & \\
\hline 4. Perceived Ease of Use (PEU) & 0.18 & 0.28 & 0.26 & 0.89 & & & & \\
\hline 5. Perceived Usefulness (PU) & 0.18 & 0.61 & 0.40 & 0.36 & 0.77 & & & \\
\hline 6. Perceived Risk (PR) & 0.38 & 0.09 & -0.06 & 0.10 & 0.02 & 0.95 & & \\
\hline 7. Perceived Trust (PT) & 0.14 & 0.62 & 0.50 & 0.28 & 0.64 & -0.10 & 0.84 & \\
\hline 8. Risk-taking propensity (RTP) & -0.37 & 0.22 & 0.44 & 0.15 & 0.25 & -0.18 & 0.30 & 0.91 \\
\hline
\end{tabular}

Notes: All correlations are significant at $p<0.01$ (two-tailed test). The square root of the average variance extract is presented in bold characters on the diagonals in the correlation matrix 


\section{References}

Abrams, R. (2014, August 8). Strategies: Facebook can deliver more than 'likes.' USA Today, Retreived from http://www.usatoday.com/story/money/columnist/abrams/2014/08/08/smallbusiness-facebook-marketing/13713285/

Aboelmaged, M., \& Gebba, T. R. (2013). Mobile banking adoption: An examination of technology acceptance model and theory of planned behavior. International Journal of Business Research and Development, 2(1), 35-50.

Alsajjan, B., \& Dennis, C. (2010). Internet banking acceptance model: Cross-market examination. Journal of Business Research, 63(9), 957-963.

Anderson, C. L., \& Agarwal R. (2010). Practicing safe computing: A multimedia empirical examination of home computer user security behavioral intentions. MIS Quarterly, 34(3), 613643.

Aral, S., Dellarocas, C., \& Godes, D. (2013). Introduction to the special issue-Social media and business transformation: A framework for research. Information Systems Research, 24(1), 3-13.

Bagozzi, R. P. (2007). The legacy of the technology acceptance model and a proposal for a paradigm shift. Journal of the Association for Information Systems, 8(4), 244-254.

Beldad, A., De Jong, M., \& Steehouder, M. (2010). How shall I trust the faceless and the intangible? A literature review on the antecedents of online trust. Computers in Human Behavior, 26(5), 857-869.

Benson, V., Saridakis, G., \& Tennakoon, H. (2015). Information disclosure of social media users: Does control over personal information, user awareness and security notices matter? Information Technology and People, 28(3), 421-446.

Bharadwaj, A., El Sawy, O. A., Pavlou, P. A., \& Venkatraman, N. (2013). Digital business strategy: Toward a next generation of insights. MIS Quarterly, 37(2), 471-482.

Boss, S. R., Galletta, D. F., Lowry, P. B., Moody, G. D., \& Polak, P. (2015). What do users have to fear? Using fear appeals to engender threats and fear that motivate protective behaviors in users. MIS Quarterly, 39(4), 1-13.

Bruner, G. C., \& Kumar, A. (2005). Explaining consumer acceptance of handheld Internet devices. Journal of Business Research, 58, 553-558.

Bryce, J., \& Fraser, J. (2014). The role of disclosure of personal information in the evaluation of risk and trust in young peoples' online interactions. Computers in Human Behavior, 30, 299-306. 
Carr, J. C., \& Sequeira, J. M. (2007). Prior family business exposure as intergenerational influence and entrepreneurial intent: A theory of planned behavior approach. Journal of Business Research, 60(10), 1090-1098.

Chen, H., De, P., \& Yu, J. H. (2015). IT-enabled broadcasting in social media: An empirical study of artists' activities and music sales. Information Systems Research, 26(3), 513-531.

Chen, S. C., \& Dhillon, G. S. (2003). Interpreting dimensions of consumer trust in e-commerce. Information Technology and Management, 4, 303-318.

Chen, S. C., Shing-Han, L., \& Chien-Yi, L. (2011). Recent related research in technology acceptance model: A literature review. Australian Journal of Business and Management Research, 1(9), 124-127.

Chin, W. W., Marcolin, B. L., \& Newsted, P. R. (2003). A partial least squares latent variable modeling approach for measuring interaction effects: Results from a monte carlo simulation study and an electronic-mail emotion/adoption study. Information Systems Research, 14(2), 189217.

Darden, W. R., \& Dorsch, M. J. (1990). An action strategy approach to examining shopping behavior. Journal of Business Research, 21(3), 289-308.

Davis, F. D. (1989). Perceived usefulness, perceived ease of use, and user acceptance of information technology. MIS Quarterly, 13(3), 319-340.

Davis, F., Bagozzi, R. P., \& Warshaw, R. (1989). User acceptance of computer technology: A comparison of two theoretical models. Management Science, 35(8), 982-1003.

DeLamater, J. D., \& Ward, A. (Eds.). (2006). Handbook of social psychology. Springer: Hoboken, NJ.

Dinev, T., Goo, J., Hu, Q., \& Nam, K. (2009). User behaviour towards protective information technologies: The role of national cultural differences. Information Systems Journal, 19(4), 391412.

Dinev, T. (2014). Why would we care about privacy? European Journal of Information Systems, 23(2), 97-102.

Fayolle, A., \& Liñán, F. (2014). The future of research on entrepreneurial intentions. Journal of Business Research, 67(5), 663-666.

Fishbein, M., \& Ajzen, I. (1975). Belief, attitude, intention, and behavior: An introduction to theory and research. Reading, MA: Addison-Wesley. 
Frambach, R. T., \& Schillewaert, N. (2002). Organizational innovation adoption: A multi-level framework of determinants and opportunities for future research. Journal of Business Research, 55(2), 163-176.

Fu, J. S., \& Shumate, M. (2017). News media, social media, and hyperlink networks: An examination of integrated media effects. The Information Society, 33(2), 53-63.

Geisser, S. (1975). A predictive approach to the random effect model. Biometrika, 61(1), 101-107.

George, J. F. (2004). The theory of planned behavior and Internet purchasing. Internet Research, $14(3), 198-212$.

Grégoire, Y., \& Fisher, R. J. (2006). The effects of relationship quality on customer retaliation. Marketing Letters, 17(1), 31-46.

Ha, S., \& Stoel, L. (2009). Consumer e-shopping acceptance: Antecendants in a technology acceptance model. Journal of Business Research, 62(5), 565-571.

Hansen, J. M., \& Levin, M. A. (2010). Retail e-learning assessment effectiveness: Motivation, location, and perception. International Journal of Retail \& Distribution Management, 38(10), 789-805.

Hansen, J. M., \& Levin, M. A. (2016). The effect of apathetic motivation on employees' intentions to use social media for businesses. Journal of Business Research, 69(12), 6058-6066.

Hansen, T., Jensen, J. M. L., \& Solgaard, H. S. (2004). Predicting online grocery buying intention: A comparison of the theory of reasoned action and the theory of planned behavior. International Journal of Information Management, 24(6), 539-550.

Henseler, J., Ringle, C. M., \& Sinkovics, R. R. (2009). The use of partial least squares path modeling in international marketing. In R. R. Sinkovics \& P. N. Ghauri (Eds.), Advances in International Marketing (pp. 277-319). Bingley, UK: Emerald.

Henseler, J., Hubona, G., \& Ray, P. (2016). Using PLS path modeling in new technology research: updated guidelines. Industrial Management \& Data Systems, 116(1), 2-20.

Hoffman, D. L., Novak, T. P., \& Peralta, M. (1999). Building consumer trust online. Communications of the ACM, 42(4), 80-85.

King, W. R., \& He, J. (2006). A meta-analysis of the technology acceptance model. Information \& Management, 43(6), 740-755.

Krejcie, R. V., \& Morgan, D. W. (1970) Determining sample size for research activities. International Journal of Human-Computer Studies, 71(12), 1144-1162. 
Kulviwat, S., Bruner, G. C., \& Al-Shuridah, O. (2009). The role of social influence on adoption of high tech innovations: The moderating effect of public/private consumption. Journal of Business Research, 62(7), 706-712.

Legris, P., Ingham, J., \& Collerette, P. (2003). Why do people use information technology? A critical review of the technology acceptance model. Information \& Management, 40(3), 191-204.

Leonardi, P. (2014). Social media, knowledge sharing, and innovation: Toward a theory of communication visibility. Information Systems Research, 25(4), 796-816.

Levin, M. A., \& Hansen, J. M. (2008). Clicking to learn or learning to click: A theoretical and empirical investigation. College Student Journal, 42(2), 665-674.

Levin, M. A., Hansen, J. M., \& Laverie, D. (2012). Toward understanding new sales employees' participation in marketing-related technology: Motivation, voluntariness, and past performance. Journal of Personal Selling \& Sales Management, 32(3), 379-393.

Liu, C., Marchewka, J. T., Lu, J., \& Yu, C. S. (2004). Beyond concern: A privacy-trust-behavioral intention model of electronic commerce. Information \& Management, 42(1), 127-142.

Luo, X., \& Lai, F. N. (2017). Social Commerce and Social Media: Behaviors in the New Service Economy. Information and Management, Available at: https://www.journals.elsevier.com/information-and-management/call-for-papers/socialcommerce-and-social-media-behaviors-in-the-new-service

Ma, Q., \& Liping, L. (2004). The technology acceptance model: A meta-analysis of empirical findings. Journal of End User Computing, 16(1), 59-72.

MacMillan, K., Money, K., Money, A., \& Downing, S. (2005). Relationship marketing in the notfor-profit sector: An extension and application of the commitment-trust theory. Journal of Business Research, 58(6), 806-818.

Mathieson, K. (1991). Predicting user intentions: Comparing the technology acceptance model with the theory of planned behavior. Information Systems Research, 2(3), 173-191.

McKnight, D. H., Choudhury, V., \& Kacmar, C. (2002). Developing and validating trust measures for e-commerce: An integrative typology. Information Systems Research, 13(3), 334-359.

Miao, C. F., Evans, K. R., \& Zou, S. (2007). The role of salesperson motivation in sales control systems-Intrinsic and extrinsic motivation revisited. Journal of Business Research, 60(5), 417425.

Mitra, S., \& Ransbotham, S. (2015). Information disclosure and the diffusion of information security attacks. Information Systems Research, 26(3), 565-584. 
Muk, A., \& Chung, C. (2015). Applying the technology acceptance model in a two-country study of SMS advertising. Journal of Business Research, 68(1), 1-6.

Palmatier, R. W. (2016). Improving publishing success at JAMS: Contributions and positioning. Journal of the Academy of Marketing Science, 44(6), 655-669.

Pavlou, P. A., \& Fygenson, M. (2006). Understanding and predicting electronic commerce adoption: An extension of the theory of planned behavior. MIS Quarterly, 30(1), 115-143.

Podsakoff, P. M., MacKenzie, S. B., Lee, J. Y., \& Podsakoff, N. P. (2003). Common method variance in behavioral research: A critical review of the literature and recommended remedies. Journal of Applied Psychology, 88(5), 879-903.

Podsakoff, P. M., MacKenzie, S. B., \& Podsakoff, N. P. (2012). Sources of method bias in social science research and recommendations on how to control it. Annual Review of Psychology, 63(1), 539-569.

Porter, C. E., \& Donthu, N. (2006). Using the technology acceptance model to explain how attitudes determine internet usage: The role of perceived access barriers and demographics. Journal of Business Research, 59(9), 999-1007.

Posey, C., Lowry, P. B., Roberts, T. L., \& Ellis, T. S. (2010). Proposing the online community self-disclosure model: The case of working professionals in France and the UK who use online communities. European Journal of Information Systems, 19(2), 181-195.

Ringle, C. M., Wende, S., \& Will, A. (2005). SmartPLS (Version 2.0 (beta)). Hamburg, Germany: SmartPLS.de. Retrieved from http://www.smartpls.de.

Saridakis, G., Benson, V., Ezingeard, J. N., \& Tennakoon, H. (2015). Individual information security, user behaviour and cyber victimisation: An empirical study of social networking users. Technological Forecasting and Social Change, 102(C), 320-330.

Schepers, J., \& Wetzels, M. (2007). A meta-analysis of the technology acceptance model: Investigating subjective norm and moderation effects. Information \& Management, 44(1), 90103.

Smith, D. N., \& Sivakumar, K. (2004). Flow and Internet shopping behavior: A conceptual model and research propositions. Journal of Business Research, 57(10), 1199-1208.

Smith, J. H., Dinev, T., \& Xu, H. (2011). Information privacy research: An interdisciplinary review. MIS Quarterly, 35(4), 989-1015.

Souza, Z. D., \& Dick, G. N. (2009). Disclosure of information by children in social networking-not just a case of "you show me yours and I'll show you mine." International Journal of Information Management, 29(4), 255-261. 
Stone, M. (1974). Cross-validity choice and assessment of statistical predictions. Journal of the Royal Statistical Society, 36(2), 111-147.

Szajna, B. (1996). Empirical evaluation of the revised technology acceptance model. Management Science, 42(1) 85-92.

Taylor, S., \& Todd, P. A. (1995). Understanding information technology usage: A test of competing models. Information Systems Research 6(2), 144-176.

Venkatesh, V., \& Bala, H. (2008). Technology acceptance model 3 and a research agenda on interventions. Decision Sciences, 39(2), 273-315.

Venkatesh, V., \& Davis, F. D. (2000). A theoretical extension of the technology acceptance model: Four longitudinal field studies. Management Science, 46(2), 186-204.

Venkatesh, V., Morris, M. G., Davis, G. B., \& Davis, F. D. (2003). User acceptance of information technology: Toward a unified view. MIS Quarterly, 27(3), 425-478.

Venkatesh, V., Tarn, K. Y., \& Hong, S. J. (2010). Model of migration and use of platforms: Role of hierarchy, current generation, and complementarities in consumer settings. Management Science 56(8), 1304-1323.

Venkatesh, V., Davis, F. D., \& Morris, M. G. (2007). Dead or alive? The development, trajectory and future of technology adoption research. Journal of the Association for Information Systems, $8(4), 267-286$.

Wang, J., Xiao, N., \& Raghav Rao, H. (2015). Research note-An exploration of risk characteristics of information security threats and related public information search behavior. Information Systems Research, 26(3), 619-633.

Wixom, B. H., \& Todd, P. A. (2005). A theoretical integration of user satisfaction and technology acceptance. Information Systems Research, 16(1), 85-102.

Wold, H. O. (1982). Soft modeling: The basic design and some extensions. In H. O. Wold \& K. G. Jöreskog (Eds.), Systems Under Indirect Observations, Part II (pp. 1-54). Amsterdam, North-Holland: Elsevier Science Ltd.

Xu, C., Ryan, S., Prybutok, V., \& Wen, C. (2012). It is not for fun: An examination of social network site usage. Information \& Management, 49(12), 210-217.

Yan, L., \& Tan, Y. (2014). Feeling blue? Go online: An empirical study of social support among patients. Information Systems Research, 25(4), 690-709. 
Yang, B., Kim, Y., \& Yoo, C. (2013). The integrated mobile advertising model: The effects of technology-and emotion-based evaluations. Journal of Business Research, 66(9), 1345-1352.

Zhou, T. (2010). Understanding users' initial trust in mobile banking: An elaboration likelihood perspective. Computers in Human Behavior, 28(4), 1518-1525. 